\title{
Construction of Quality Management System of Higher Educational Administrations Based on the ISO9000 Groups of Standards
}

\author{
Qinde Mo \\ President's Office, Guangxi University of Science and Technology, Liuzhou 545006, Guangxi \\ E-mail: 329504179@qq.com
}

\begin{abstract}
Quality management of higher educational administration is an important system for universities and colleges. It is imperative to explore the possibility for improvement of the system. By combining with the ISO9000 groups of standards and higher educational administration, both the introduction of ISO9000 quality management and establishing quality management system of higher educational administration work are investigated from the aspects of element design and documents compiling of the quality management system in this work. Thus, a guideline is put forward for the system.
\end{abstract}

Keywords-the ISO9000 groups of standards; Higher educational administration; Quality management

\section{INTRODUCTION}

Higher educational quality administration based on the ISO9000 groups of standards refers to a management that comprehensive management is achieved by introducing the ISO9000 groups of standards and further establishing quality management [1-3]. Lots of universities overseas have obtained desirable results by applying the ISO9000 groups standards since 1990's. Recently, some universities at home have also achieved scientific, standard management of education quality successfully via experiencing the ISO9000 groups standards. However, the effects are not so satisfactory. Some arguments such as the suitability of the ISO9000 to education last till the present. The author believes that the ISO9000 groups standards are universal, and therefore, it must be suitable for education completely, especially for higher educational administration. By combining with the ISO9000 groups of standards and higher educational administration practical works, both the introduction of ISO9000 quality management and establishing quality management system of higher educational administration work were investigated from the aspects of element design and documents compiling of the quality management system.

\section{ELEMENT DESIGN Of Higher EDUCATIONAL QuALITY MANAGEMENT}

To introduce the ISO9000 groups standards and further establish quality management successfully, it is necessary to combine with self practical conditions and distinguish quality management terms for each organization, which is the premise and prerequisite for the establishment of quality management.
Also, it insures the quality management success to distinguish and understand the terms.

\section{A. Identification of The Main Products in Higher Educational Administration}

The producer, viz. the educators, and the consumer of the products, viz. both the university students and teachers, for higher educational administration are two respects of the same question. From the point view of production and consumption, the educational administration could be divided into two procedures of providing service or productions, and the consumption of the productions. The author thinks that, college educational administration work into ISO9000 series standard set up quality control system, have to the two process comprehensive to identify, this is education by the particularity of the school and the nature of the "customers" of the decision.

Firstly, the main contents that educational administration offers should be confirmed. With regard to the ISO9000 groups of standards, the productions could be classified four kinds, in which education belongs to service. "The service is commonly invisible, and at least one interaction must be finished in the process of providing and consumption." [1]. Thus, the products in universities are the interaction of delivery of invisible products and creation suitable atmosphere, which are the soul of universities' educational administration. In another word, the goal of the educational administration is to provide kinds of suitable conditions for both the undergraduate and the college teachers. According to the ISO9000 groups of standards, the "products" provided by higher educational administration includes:

1. Teaching-affair management staff;

2. Hardware facilities, such as classroom, laboratory, network platform, etc;

3. Education management information system, including establishing the instruction scheme, curriculum, examination, enrollment, teaching materials, and teaching quality and supervision systems.

Secondly, the services accepted by the undergraduates and college teachers should be positioned properly.

Undergraduates are the soul of study, and college teachers are the subject of teaching. They are both the customer who receives the provided services. Moreover, both of them consume the services actively instead of passively. The main 
procedures when both the undergraduates and the college teachers consume the services are as following:

1. Evaluation and selection of service standard and attitude of teaching-affair management staff;

2. Application of the hardware;

3. Application of the education management information system;

In brief, according to the ISO9000 groups of standards, it is imperative to keep the factors that may affect the teaching-affairs under control so as to ensure excellent management quality. Therefore, it is the preconditions of establishing, maintaining and improving higher educational administration to investigate all the procedures that effect the administrations and the interactions between the mentioned procedures by applying the system method of management.

\section{B. Identification of the main procedures in higher educational administration}

The ISO9000 groups of standards is composed by the following four processes of management duties, resource management, product implementation, and quality measurement, analysis, and improvement. The purpose of all the processes is to focus on the customers' requirements, to offer the customers high-quality products by improving the quality evaluation measurements and analyst methods.

Based on the ISO 9000 groups of standards, combining the practice of higher educational administration, it is considered that higher educational administration is composed of six procedures which are as follows:

1. Educational environment creation:

(1) Hard environment, such as educational settings, teaching and practice equipment and facilities, and campus network platform, etc.

(2) Soft environment, such as educational administration management institutions.

2. Management of educational administrators: Such as the selection, training, and management of administrators, as well as supply of facilities.

3. Students' management: such as students' admission, registration, and roll management.

4. Course management: such as developing teaching program, arrangement of syllabus, etc.

5. Evaluation of teaching quality, composing of assessment of homework, dissertation supervision, examination, and supply of teaching materials.

6. Management of graduates: such as graduation qualification, validation of degree, and gradating for university.

The mentioned six procedures belong to the management functions, resource management, implementation of products, and measurement and improvement courses of the quality of ISO9000 groups of standards.

\section{Design of basic elements of educational administration management in university}

It is obvious from the above details that higher educational administration is composed of six subsystems of educational environment creation, management of educational administrators, students' management, course management, evaluation of teaching quality, and management of graduates [5-7]. Each subsystem is implemented via documented procedure programmatically. The whole procedure is of closed-loop system for the overall system and its subsystems, and an integrated quality management documents are demanded.

The quality management system could be constructed successfully when the mentioned procedures are analyzed and the interactions of them are further investigated. Thus, effective control to each procedure could be achieved by establishing quality management system documents, resulting in the successful quality management. Therefore, it is obvious that accurate definition and optimal design of basic elements of educational administration management are of vital importance. According to the ISO9000 groups of standards, educational administration management in university is composed of the general demands, management responsibility and commitment, quality policy and goals, planning and evaluation, resource management, realization of educational service, and the measurement and further improvement of educational administration management.

\section{PREPARATION OF DOCUMENTS OF EDUCATIONAL ADMINISTRATION QUALITY MANAGEMENT}

Higher educational administration management relies on strict and standard documents system [8,9]. Therefore, the administration documents must prepared according to the ISO9000 groups of standards, combining with the nature and practice of higher education. Moreover, the documents which are considered as management tool and measurement provide a guideline for the administration affairs [2-4].

\section{A. Composition and features of the educational administrative management file system}

The ISO9000 groups of standards verifies the following kinds of files: (1) quality manual which provides information to both internal and external of the organization; (2) quality plan which reveals how the quality management system is applied to particular products, projects, etc.; (3) specifications which clarifies the demands of the system; (4) guidelines which offers methods and/or advice; (5) preparation of documents and working instructions which guide the activities to be completed; and (6) documentations which is applied to evaluate the results reasonably.

According to the ISO9000 groups of standards, the documentations could be divided into four layers. The top layer works as a guide. The lower the layer is, the more definite and detailed it will be, and the more operational. In another word, the lower the documentation level is, the more the amount will be. Except the documents that meets the demands of quality management, the related laws and regulations of university are also required for higher educational administration. 
The ISO9000 groups of standards is actually a documentation system which is composed of the guiding documents, the indicative documents, the executive documents, and the recorded documents. Thus, the educational administration management system based on the ISO9000 groups of standards is documentation featured consistent, systematical, legally authoritative, compatible, successive, practical, scientific, gradational, relatively stable, and improved.

\section{B. Fundamental principles for preparing the educational administration management documents}

The educational administration document is not only the rule for maintaining the educational administration quality, but also that for internal audit and certification of quality management. Therefore, some principles must be followed when preparing the documents [10]:

- Full participation. Educational administrations that ensure the management procedures to be operated successfully are an important basis to master the organization and locate oneself within the system. Therefore, it is imperative to be enrolled for more staff while preparing the documents. Moreover, participating in the documenting could help the staff to execute the rules.

- Integrating theory with practice. Preparing the documents of educational administration quality should be integrated with the real situation of each university except the ISO9000 standard and the quality manual. In another word, once the quality of educational administration is achieved successfully by preparing kinds of documents, the desired goals are reached.

- Simplicity and validity. The educational administration files must be integrated with practice, instead of becoming isolated from reality. The prepared documents should provide the staff proper information concisely. The forms that the documents present could vary greatly, such as figure, photo, cartoon, and other kind of files.

- Standardization and scientificalization. Although the quality management documents are an organic whole, each document should be prepared based on its role and requirements, which is determined by the performance of the quality management files.

- Harmony and unity. The educational administration documents are a system file. Therefore, each level's document must be consistent in style, structure, pattern, and term. Moreover, the quality manual, the files, and the instructions should be consistent with the ISO9000 groups of standard in style.

\section{Preparing of educational administration documents}

The higher educational administration is executed by preparing relative documents according to the ISO9000 groups of standard. The quality administration system is composed of quality policy and objective, quality manual, documents, relative laws, and regulations of each university. The documents could be adjusted according to the reality.

\section{1) Updating the quality manual}

Quality manual is the soul of the educational administration system. The quality management system of relative processes and their relationship should be described within the manual. The purpose of preparing the manual is to ascertain the quality control, policy, objectives, organizational structure, and the requirements, which in turn provides feasible measures for successful quality control in educational administration. In preparing the manual, except the mentioned above, the following problems should also be considered: ( 1 the standard structure of the quality manual; (2) the responsibilities by ascertaining the duty of each task; (3) the programmatic characteristics of the manual by classifying the manual reasonably; (4) the interaction of each functions overall; (5) the mutual relations by citing; (6) the reason if the procedures should be cut; and (7) the grammar.

\section{2) Preparing the procedure documents}

Procedure documents which belong to the second level within the documents are directive. The procedure is defined as a process that when certain activity is conducted, it may experience. Procedure documents are the important part of quality management system. It is usually composed of the goal and range of certain activity, what to do and who will do it, when, where and how to engage, what materials of equipments should be used, and how to realize and control the activity. As the procedure documents are a guide for quality manual, it should be prepared according to the quality manual as well as the reality. It makes sure that the documents involve control, record, auditing, correction of measures, and preventive measures according to the ISO9000 groups of standards.

Although the educational administration documents could be prepared in correlated with the reality of each university, it is imperative that the documents should cover the activities of the university completely. From the perspective of educational administration, the more detailed the documents is, the better result could be reached. Thus, the documents involved in the goal, range of application, duty, procedure, and the relative files and records.

When preparing the documents, the executive process of should be distinguished as it is the third layer of the system. Flow chart can be used to demonstrate the procedures concisely, thus it could be engaged to describe the process and each activity. Once the process is declared, the goal, range of application, and duty could be improved. Therefore, the quality management documents could be further developed.

\section{3) Compiling of work instruction}

The work instruction is of performance and support, which will deal with the problem of how to do. It mainly refers to the position duty and kinds of regulations.

Work instructions should describe the process and the operational methods in detail as it is the guide for the site staff correlated to the work. Therefore, whether it is proper and/or 
targeted will affect the result greatly. There are lots of work instructions in educational administration system. The preparation of the work instructions will vary with their functions greatly because the data that the instructions are prepared according to will affect the effectiveness and suitability of the instructions greatly. Therefore, proper and practical data should be selected when preparing the instructions so as to ensure its sufficiency and practicality.

The instructions aim to describe how the procedures should be proceeded with. The instructions should keep excellent compatibility and harmony with the other documents. Moreover, the instructions should not only illustrate the thing to be done according to its structure and contents, but also be of maneuverability and delectability.

In short, preparation of documents should be considered as a value-added activity. The purpose of establishing the quality management system is to benefit the customs, university, and staff, and thus, the quality could be improved continuously. The system documents, as a guide of establishing, executing, and maintaining of the system, could be used as a measure to gain both the students' and the staff's trust, and to improve the quality management of the university [11]. Hence, the soul of preparing the documents is "communicating the intents, uniforming the actions". Therefore, when preparing the documents, concise and clear goal, standard, and measure should be provided [3].

\section{CONCLUSIONS}

The educational administration quality management system based on the ISO9000 groups of standards is documented. A proper document will lead to higher efficiency. The quality management system should be established according to the reality of each university besides the quality policy, goal, manual, and the mentioned six process files. As long as the educational administration quality and the quality management system could be executed successfully, a concise and relative fewer documents would result in higher efficiency [4,5,7].

Meanwhile, it is imperative to synthesize the requirements of the ISO9000 groups of standards and the educational administration and the relationship between each subsystems in quality managements and educational administration. The mentioned two aspects are the two pillars for the whole management procedures. Establishing the educational administration system based on the ISO9000 groups of standards and higher education and teaching rules, is the soul in engaging university.

\section{REFERENCES}

[1] The People's Republic of China. The quality control system standard GB/T19000-2008. Beijing: China Standard Press, 2009

[2] S. Wu, Quality Management system documents and its Preparation (New Ed.). Shanghai Quality. 2001 (1)

[3] Z. Zhao, School Management Systems and the ISO9000 Groups of Standards__ A case of Jiangyin Senior Middle School. Shanghai: East-China Normal University Press, 2003, p145

[4] R.P. Singhal, "Building up Capabilities of Educational Administrators in India," International Journal of Educational Development, Vol. 3, 1983, pp 61-70

[5] J. Yan, "Design and Implementation of Educational Administration System on the Basis of C/S and B/S Heterogeneous Architecture,"
Communications in Computer and Information Science, Vol. 243, 2011, pp 473-481

[6] A. McClelland, P. Juliff, "Telecommunications in Educational Administration and Management of Learning in Higher Education," IFIP Advances in Information and Communication Technology, 1995, pp 246-248

[7] L. Liu, S. Ji, "Design and Development of University Educational Administration Information System Based on J2EE," Lecture Notes in Electrical Engineering, Vol. 113, 2012, pp 355-362

[8] J. Gairín, D. Rodríguez-Gómez, "Leadership, Educational Development, and Social Development", Springer International Handbooks of Education, Vol. 29, 2014, pp 819-843

[9] J. K. Chen, I. S. Chen, “A network hierarchical feedback system for Taiwanese universities based on the integration of total quality management and innovation", Applied Soft Computing, Vol. 12, August 2012, pp 2394-2408

[10] A. V. Todorut, "The need of Total Quality Management in higher education", Procedia-Social and Behavioral Sciences, vol. 83 , 2013, pp $1105-1110$

[11] A. J. Walker, "Impact of an ISO9001 compliant quality management system on a university research enterprise", University of the Witwatersrand, Johannesburg, vol. 9, 1997, pp397-402 